\title{
Multi-objective optimization of time-cost-quality in construction projects using genetic algorithm
}

\author{
Setenay Isikyildiz (Main Author) \\ Department of Civil Engineering, Istanbul University-Cerrahpasa \\ Istanbul, 34320 (Turkey) \\ setenay.reman@gmail.com \\ https://orcid.org/0000-0002-0427-6122
}

Cemil Akcay (Corresponding Author)

Faculty of Architecture, Istanbul University

Istanbul, 34116 (Turkey)

cakcay@istanbul.edu.tr

https://orcid.org/0000-0002-8216-8688

Manuscript Code: 13854

Date of Acceptance/Reception: 24.11.2020/21.02.2020

DOI: 10.7764/RDLC.19.3.335

\begin{abstract}
In this study, it was aimed to develop a model that provides Time-Cost-Quality optimization in construction projects using the genetic algorithm method. To fulfill that, Matlab codes for a multi-purpose genetic algorithm that performs Time-Cost-Quality optimization were developed and applied to the problem, and the targeted success level was substantially achieved. This model is capable of performing and visualizing an advanced threedimensional time, cost, quality tradeoff analysis instead of the traditional two-dimensional time-cost tradeoff analysis. It was possible to select the desired alternative under the project conditions obtaining Pareto images called a set of solutions rather than a single solution. In addition, one of the main objectives of this study is to develop an effective model to assist the main contractors of the construction in selecting the most suitable subcontractors.
\end{abstract}

Keywords: Time-cost-quality trade-off, Multi-objective optimization, Meta-heuristic, Genetic algorithm, Subcontractor selection.

The main purpose of a project is to complete the planned works at the desired time, cost, and quality. Construction projects consist of hundreds of activities that take place within a certain organization and model. These activities are linked to each other in order. Each activity might have multiple alternatives for cost, time, and quality. The larger the project, the more difficult it is to make a choice between these alternatives. Many different numbers of time, cost, and quality options might come out. It becomes impossible to estimate the amount of time and resources allocated for the project. For the projects of which are planned to satisfy minimum time, minimum cost, and maximum quality, no point meets these three conditions. As the cost decreases, the duration of the project may increase or the quality may decrease. It is required to increase the cost in order not to decrease the quality while the project duration shortens. It is impossible to find a solution that meets all of these criteria consisting of minimum time, minimum cost, and maximum quality. Therefore, it may be expected to concentrate the project manager's attention on one of these characteristics depending on the project properties. Since there are hundreds of activities in a project and different time, cost and quality options for each activity exist, it is difficult to make an appropriate choice. Utilizing algorithms, it becomes possible to obtain the desired result from thousands of alternatives. The project progress can be regulated by determining which characteristics of the projects are more important.

A significant amount of research has been done in the area of optimization for the use of construction resources. Numerous studies have been conducted in the literature to minimize cost and time, which is one of the optimization problems. In addition, project applications and benefits have been widely observed. However, few studies are available in the literature on the problem of time-cost-quality optimization. Current research in the literature brought about a series of optimization models developed using a variety of methods, including linear programming, integer programming, dynamic programming, heuristic, and meta-heuristic algorithms. These models can be classified as follows according to optimization objectives: i) Models that minimize project duration and/or improve resource utilization and, ii. Models that minimize time and/or cost for construction projects using time-cost trade-off analysis (Aminbakhsh et al., 2016; Easa, 1989; B. K. El-rayes, 2001; Geem, 2010; Gomar et al., 2002; Hegazy, 1999; Hegazy \& Wassef, 2001; Magalhães-mendes, 2017; Zalmai et al., 2019; Zhang \& Li, 2010; Zheng et al., 2005). 
Although these studies have contributed significantly to optimizing the use of construction resources, few studies are focusing on multi-purpose models to optimize construction time, cost, and quality. A study in which a fuzzy logic system was applied for different construction methods with different project duration, cost, and quality values exist (Iscioglu, 2011). Zhang et al worked on a combined optimization model in their research and applied this combined model which is based on the time-cost and quality-time system [13]. Bingol and Polat applied particle swarm optimization for time, cost, and quality optimization in subcontractor selection in their studies (Bingol \& Polat, 2015). Similarly, Vedat and Azim proposed a model that provides time-cost-quality optimization in construction projects using the Teaching Learning Based Optimization method (Togan \& Eirgash, 2019).

In recent years, literature has mostly focused on analyzing time and cost with little reported research on models for optimizing construction time, cost, and quality together. Within the scope of this study, a multi-purpose and multialternative model that makes time-cost-quality optimization using the genetic algorithm method which is one of the meta-heuristic algorithms has been established. In order to measure the quality, the quality criteria, and weight ratios for these criteria were determined with experts' opinions by a survey. Following this, Matlab codes of an algorithm providing Pareto solutions inconsistent with the problem were written. In projects with a multi-purpose and multialternative problem, a case for a time, cost, and quality optimization were solved by trying to use different population values and the results were evaluated.

State of Art

\section{Review on Optimization Algorithms}

Optimization problems are generally considered as deterministic and stochastic in two main categories (Table 1). In the deterministic approach, while solutions are made by classical methods taking into account the known parameters, the variables that may occur in the design are not considered, whereas the variables in the stochastic approach are taken into account.

Table 1. Categorization of optimization algorithms (Yang, 2010).

\begin{tabular}{ll}
\hline Deterministic & Stochastic \\
\hline Linear programming & Heuristic \\
\hline Non-linear programming & Metaheuristic \\
\hline Gradient-based & \\
\hline Free of gradient & \\
\hline${ }^{*}$ Population-based, Trajectory-based \\
\hline
\end{tabular}

The mathematical programming problem consists of optimizing a goal function under certain constraints. Heuristic methods are algorithms based on natural phenomena to accomplish any purpose or goal, and these algorithms generally provide good solutions but do not consider optimality. For this reason, the exact solution is not obtained because the heuristic algorithms have the convergence feature, so a solution is obtained near the exact solution.

Metaheuristic methods aim to combine basic heuristic methods that will enable the search for solution space efficiently. In this respect, these methods are general purpose heuristics designed to guide probing-specific intuitions to perform searches in regions of high-quality solutions of search space (Dorigo \& Stutzle, 2004). Top-heuristic algorithms; is a decision mechanism that works on heuristic algorithms.

Meta-heuristic methods are the establishment of new approximate methods that combine basic heuristic methods allowing to effectively scan the solution space (Dorigo \& Stutzle, 2004). Meta-heuristics are general-purpose heuristic methods created because of leading problem-specific heuristics to perform a search in areas of search space containing high-quality solutions. Meta-heuristic algorithms are decision making systems that work on heuristic algorithms. In other words, when it is assumed that three different methods can be applied for a problem and all of these methods are heuristic algorithms that are advantageous in terms of different purposes, it is called a metaheuristic algorithm to decide which one will be preferred. Numerous methods have been developed for the solution in various fields and these methods have been revised according to special conditions of the problem. Thus, there is no need to make a selection between multiple solution methods for a problem. Simply, a meta-heuristic algorithm makes a choice between existing algorithms and applies the most successful one. This system which decides the most appropriate algorithm generally works according to statistical information. In the literature, meta-heuristic techniques commonly used in solving optimization problems are taboo search algorithm, ant colony optimization, genetic algorithm, artificial neural 
networks, and particle swarm optimization. These methods vary by performance depending on the optimization problem for which they find a solution.

Genetic algorithms are search and optimization tools used in project planning and control. The genetic algorithm helps to identify optimal or near-optimal solutions for problems with large search space (Sorrentino, 2013). GA is also a widely used algorithm for complex problems (Deb et al., 2002). The genetic algorithm (GA) can use discrete, continuous relationships and linear and nonlinear functions can be implemented in it (Sivanandam, \& Deepa, 2008). Different kinds of algorithms can be merged with GA. The GA can solve various types of problems very easily and effectively because complex calculations are not required. Thus, this study was used because of its simplicity and versatility. Due to its simplicity and versatility, the genetic algorithm is convenient for this study.

\section{Methodology}

This study aims to provide a multi-purpose multi-alternative optimization model that supports minimizing construction time and cost while maximizing quality. The developed optimization model used the Pareto optimality principles shown (in Figure 1) to find optimum results within a wide range of possible solutions. The model produces not only one optimum result but also an optimal set of solutions. Therefore, the most appropriate solution set will be available according to the parameter that the manager gives priority.

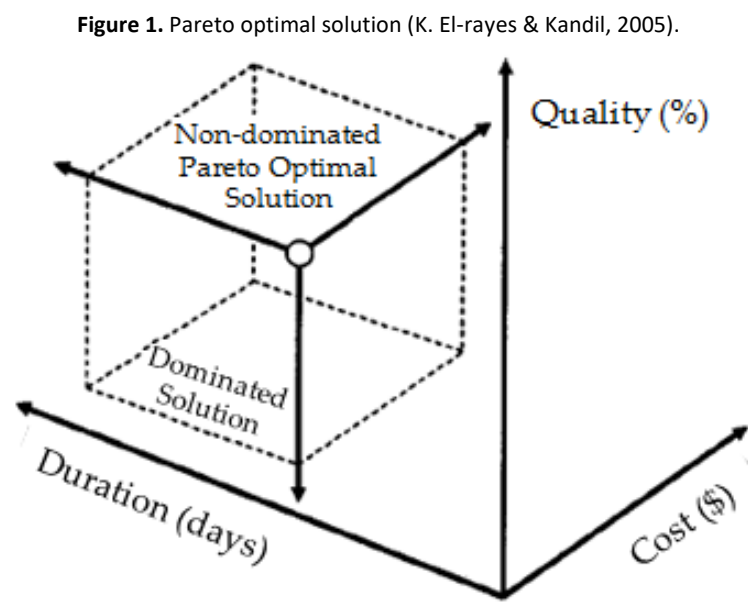

Generally, the main contractors tend to have the subcontractors do some work items for the construction project. In such cases, the selected subcontractors are responsible for the quality of the work. Accordingly, the success of a construction project and, hence the success of the main contractor, depends highly upon the performance of the subcontractors. Therefore, one of the major problems that the main contractor encounters is the selection of the most appropriate subcontractors for each work packages. In most cases, the main contractors make this decision at the beginning of the project and they have to evaluate the performance of the subcontractors in terms of time, cost, and quality in the process of selection. Following this selection procedure, an optimal combination of subcontractors to carry out the different workgroups in the project is selected. For the contractors, in general, it is difficult to select the most appropriate combination that balances the time-cost-quality trade-off. One of the main objectives of this study is to assist in the selection of the subcontractors which provide optimum time-cost-quality according to the parameter that the manager gives priority by utilizing the experience data of the companies. In this study, the genetic algorithm method was considered and applied to the problem.

\section{Genetic Algorithm}

A genetic algorithm is a meta-heuristic approach that enables the optimization of complex and difficult problems. This procedure is based on the principle of survival of the strong through some operators mimicking nature (Goldberg, 1989). Genetic algorithms are natural selection mechanics and natural genetics-based search algorithms. In order to build a search algorithm with an innovative design, the survival of the best of the array structures is combined with random information exchange. In each new generation, a new artificial population is created using the characteristics of the most talented and surviving individuals and, occasionally, random changes can be done in genetic information for better results. The problem is optimized by using previous information obtained from the population efficiently at new search points. Genetic algorithm is a search and optimization tool used in project planning and control. It assists to identify optimal or near optimum solutions for problems with large search space (Sorrentino, 2013). 
Genetic algorithms have many advantages over traditional optimization algorithms and the most notable advantage is the ability to cope with parallelism and complex optimization problem. Genetic algorithms can address various types of optimization of the fitness function, such as stationary or non-stationary, linear or nonlinear, continuous or discrete. Since the generations in a population act as independent agents, the population (or any subgroup) can explore the search area in many ways at once. However, genetic algorithms have also some disadvantages. Selection of important parameters such as formulation of the fitness function, the use of population size, mutation and crossover rates, and selection criteria of the new population should be carefully determined. Any inappropriate selection might make it difficult to combine the algorithm or produce meaningless results. Despite these disadvantages, genetic algorithms remain one of the most widely used optimization algorithms in modern nonlinear optimization (Yang, 2010).

GA is a search technique used to find optimum or near-optimal solutions for optimization problems. GA searches for a global optimum with a meiosis-based algorithm. The first population is randomly generated and new genes are reproduced by crossover. Genetic differences are caused by mutation and inappropriate genes are eliminated with natural selection procedures (Bettemir, 2011). Concepts for genetic algorithms and definitions regarding operators are given in the Appendix. In a standard GA, candidate solutions (individuals) are expressed as binary vectors in equal size. Initially, a group of these vectors is selected randomly to create a population of a certain size. Vectors called chromosomes allow the development of new populations as a result of evolutionary mechanisms. The genes on the chromosome represent a dimension of a vector with ' $n$ ' dimensions (Sari, 2008). The first step of GA is the production of the initial population. The determination of population size is extremely important. Large populations require heavyload calculations and small populations have the critical risk of concealing the solution (Bettemir, 2011). The fitness function generates an output from the input variables (chromosomes) in an array form. The fitness function can be a mathematical function, an experiment or a game. The objective is to modify the output as desired by finding the most appropriate values in the inputs. GA begins with the definition of a chromosome or a sequence of chromosomes or an array consisting of variables to be optimized. If a chromosome has $\mathrm{N}$ variables in a form of $\mathrm{P} 1, \mathrm{P} 2, \ldots, \mathrm{PN}$, chromosome elements are expressed as a line vector:

Chromosome $=[\mathrm{P} 1, \mathrm{P} 2, \mathrm{P} 3, \ldots, \mathrm{PN}]$

For example, searching for the maximum altitude on a topographic map requires a fitness function with longitude ( $x$ ) and latitude (y) input variables. In this case, the chromosome with $\mathrm{N}=2$ can be identified as follows:

Chromosome $=[x, y]$

Each chromosome created has a fitness value obtained from the fitness function $f$ with variables $P 1, P 2, \ldots, P N$.

Fitness value $=f($ chromosome $)=f(P 1, P 2, \ldots, P N)$

Crossover is a necessary process for genetic regeneration. The new genes are reproduced from randomly selected genes. Pairs (parents) are determined by random numbers and the new two genes are reproduced with crossover process. The crossover location is also determined by generating a random number. After the crossover, two new gene combinations are derived from the two existing gene combinations in the population. A low crossover rate is vitally important because sufficient genetic differences cannot be established and the convergence of the solution is reduced. A very high crossover rate messes up genes excessively and it prevents the chromosomes carrying the well-matched genes from reaching the global optimum. One-point, two-point and uniform crossover techniques are often used for the crossover process. The mutation prevents the dominance of a particular gene with a high probability of survival. Some well-matched chromosomes might be tripped to the local minimum. In this case, better solutions are overlooked. The mutation operator prevents tripping to possible local optimum values. A high mutation rate can lead to disruption of well-matched genes approximating to global optimum (Bettemir, 2011).

Natural selection is the final stage of the genetic algorithm cycle. Natural selection ensures that the size of the population before the crossover process remains the same as the result of the process. It also improves the overall gene quality of the population by eliminating individuals with low fitness values. On the other hand, low-fit chromosomes can carry very important genes in their certain parts and some precautions are taken during natural selection to protect these parts. In optimization algorithms, the stop criterion can be applied as i) the maximum number of iterations, ii) The value of the objective function iii) The number of consecutive iterations in which the convergence or solution does not develop, and iv) A specified time condition. 
In this study, a genetic algorithm is applied to a multi-purpose optimization problem. The data of the problem examined in Matlab code was obtained from a construction project. The problem investigated in this study consists of 15 main activities. Since the Matlab code was for trial purposes, the problem was applied with only 15 main activities without taking into account the substrates of the main activities. Table 2 presents data for activities of the problem dealt with. These data include the activity ID, the name of the activity, the activities just before the main activity, and the different time-cost-quality values up to five options for each activity. The duration and cost values of the five alternatives are obtained from subcontractors' tenders of a real construction project. These subcontractors have previously worked on different projects under the same contractor firm. The quality values of the alternatives are the average rates determined and evaluated by the main contractor technical personnel according to the standard in Table 3. CPM network and data belong to the problem are given in Figure 2.

Table 2. Problem application data for the case study (Isikyildiz, 2019).

\begin{tabular}{|c|c|c|c|c|c|c|c|c|c|c|c|c|c|c|c|c|c|}
\hline \multirow{2}{*}{ ID } & \multirow{2}{*}{ Activity name } & \multirow{2}{*}{ IP* } & \multicolumn{3}{|c|}{ Alternative 1} & \multicolumn{3}{|c|}{ Alternative 2} & \multicolumn{3}{|c|}{ Alternative 3} & \multicolumn{3}{|c|}{ Alternative 4} & \multicolumn{3}{|c|}{ Alternative 5} \\
\hline & & & $\mathrm{T}^{*}$ & $C^{*} 10^{3}$ & $Q^{*}$ & $T^{*}$ & $C * 10^{3}$ & $Q^{*}$ & $\mathrm{~T}^{*}$ & $C^{*} 10^{3}$ & $\mathrm{Q}^{*}$ & $\mathrm{~T}^{*}$ & $C^{*} 10^{3}$ & $\mathrm{Q}^{*}$ & $\mathrm{~T}^{*}$ & $C^{*} 10^{3}$ & $Q^{*}$ \\
\hline A & $\begin{array}{l}\text { Construction site } \\
\text { delivery }\end{array}$ & - & 1 & - & - & - & - & - & - & - & - & - & - & - & - & - & - \\
\hline B & Mobilization & $A$ & 7 & 20 & 80 & 5 & 24 & 70 & - & - & - & - & - & - & - & - & - \\
\hline C & Excavation & B & 15 & 300 & 80 & 17 & 285 & 95 & 14 & 320 & 85 & 12 & 330 & 70 & - & - & - \\
\hline D & Foundation & $\mathrm{C}$ & 10 & 350 & 70 & 8 & 380 & 80 & 12 & 315 & 90 & - & - & - & - & - & - \\
\hline $\mathbf{E}$ & Concrete works & $\mathrm{D}$ & 88 & 1.150 & 70 & 86 & 1.200 & 60 & 93 & 1.000 & 80 & 82 & 1.500 & 90 & - & - & - \\
\hline $\mathbf{F}$ & $\begin{array}{l}\text { Electic conduit in } \\
\text { Wall and Ceiling }\end{array}$ & $E$ & 40 & 400 & 85 & 43 & 370 & 95 & 36 & 440 & 80 & - & - & - & - & - & - \\
\hline G & Wall works & $\mathrm{F}$ & 34 & 300 & 70 & 31 & 325 & 80 & 38 & 275 & 80 & 29 & 348 & 90 & - & - & - \\
\hline H & Screed concrete & J & 15 & 120 & 80 & 17 & 100 & 90 & 12 & 145 & 70 & - & - & - & - & - & - \\
\hline I & $\begin{array}{l}\text { Heating } \\
\text { installation }\end{array}$ & G & 30 & 320 & 75 & 33 & 300 & 80 & 26 & 352 & 70 & 29 & 347 & 90 & - & - & - \\
\hline J & $\begin{array}{l}\text { Sanitary } \\
\text { installation }\end{array}$ & G & 20 & 390 & 90 & 18 & 410 & 80 & 22 & 370 & 70 & 25 & 330 & 60 & 16 & 459 & 50 \\
\hline K & Tile & $\mathrm{H}$ & 25 & 260 & 70 & 27 & 240 & 95 & 21 & 290 & 85 & - & - & - & - & - & - \\
\hline $\mathbf{L}$ & $\begin{array}{l}\text { Door and window } \\
\text { works }\end{array}$ & G & 15 & 300 & 70 & 12 & 340 & 80 & 10 & 400 & 60 & 18 & 280 & 80 & 19 & 275 & 95 \\
\hline M & Plaster works & $\mathrm{I}-\mathrm{L}$ & 55 & 190 & 80 & 57 & 170 & 70 & 49 & 275 & 90 & 59 & 150 & 60 & - & - & - \\
\hline $\mathbf{N}$ & Ceiling floor & $\mathrm{M}$ & 33 & 270 & 75 & 29 & 360 & 80 & 35 & 280 & 70 & 38 & 250 & 60 & 27 & 400 & 90 \\
\hline 0 & Satin paint & $\mathrm{K}-\mathrm{N}$ & 15 & 70 & 80 & 17 & 70 & 90 & 12 & 100 & 70 & 18 & 65 & 50 & - & - & - \\
\hline
\end{tabular}

IP*: Immediate Predecessor, $\mathrm{T}^{*}$ : Time, $\mathrm{C}^{*}$ : Cost, $\mathrm{Q}^{*}$ : Quality.

Figure 2. CPM network for the case study (Isikyildiz, 2019).

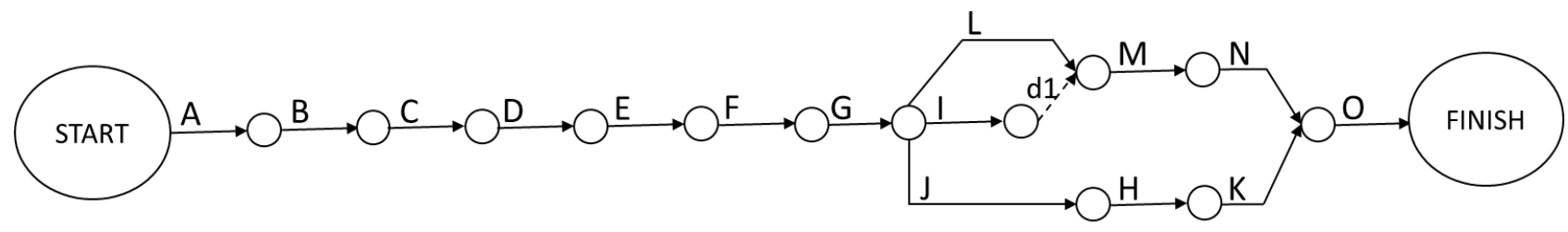

Five alternatives are corresponding to the duration, cost, and quality value of each task for 15 activities in the sample problem. When a random alternative is chosen, different times, cost, and quality components come out. Genetic algorithms would be appropriate for such multi-purpose optimization problems. The fact that quality, duration, and cost are equally important for time-cost-quality optimization problems prompted researchers to focus on multi-objective optimization problems. Revisions in the project and factors affecting the progress of the work may reveal the possibility of project completion in different time periods. It is not possible to obtain only one optimum solution for multi-purpose optimization problems. Minimum cost and maximum quality should be determined for each time period. Similarly, minimum time and minimum cost data are important for maximum quality values. The cost of the project is an important parameter, as well. 
In sample problem, it is not possible to conclude which option is essential when two options, which are i) 300 days for the project completion time, 820000 USD for cost and $90 \%$ of average quality and ii) 200 days for the project completion time, 820000 USD for cost and $82 \%$ of average quality, compared with each other. Similarly, it is not clear that which option would be advantageous comparing two conditions, which are i) 250 days for the project completion time, 820000 USD for cost and $90 \%$ of average quality and ii) 300 days for the project completion time, 700000 USD for cost and $90 \%$ of average quality. The project manager should evaluate the conditions and decide which criteria should be given weight. In problem-solving, for hundreds of project completion time, different cost values and average quality values were obtained. There is no case in which the cost and duration of the project have the lowest value and the average quality has the highest value. Therefore, some solutions cannot dominate each other. Each of these solutions cannot assert dominance over the others and, therefore, it is not possible to call one of these solutions the optimum solution. The set of solutions includes non-dominated solutions which are also called Pareto front.

\section{Quality Data of the Problem}

In the multi-purpose optimization problem investigated in this study, the main objective is to find out the Pareto solution contour, where the project activities were implemented, project duration and cost are minimum, and hence, the quality is maximum. Each activity has a multi-alternative of duration and cost. Quality ratios also vary depending on these alternatives. Quality is also effective in decision making, as the relationship between time and cost plays an effective role in the decision-making process at the beginning of project implementation. Time, cost, and quality values in projects vary depending on many factors. The evaluation criteria and weight ratios that are taken into consideration regarding quality are determined by taking expert opinions with a questionnaire study. These quality assessment experts are; project quality experts, project managers, and site chiefs who generally work on large-scale construction projects in Istanbul. We aimed to select experts working on large-scale construction projects with a construction area of at least $20000 \mathrm{~m} 2$ and above. We reached these experts with the help of the Istanbul Chamber of Civil Engineers. The results of the survey are given in Table 3.

The case study project is a seven-storeyed $(\mathrm{G}+6)$ faculty building with a construction area of $26000 \mathrm{~m} 2$, whose construction is in progress in Istanbul, Turkey. Those who make quality assessments for subcontractors are the project manager, quality control engineer, and site chief in charge of this project. In the application within the scope of the study, the data in Table 3 were used for the weighted average concerning subcontractors' quality assessment by the construction company.

\begin{tabular}{clc}
\multicolumn{4}{c}{ Table 3. Quality criteria for the case study (Isikyildiz, 2019). } \\
\hline & Criteria & Weight ratio (\%) \\
\hline 1 & Quality standard certificates & 5 \\
2 & Equipment (Technology - Innovation) & 5 \\
3 & Technical personnel capacity & 5 \\
4 & Starting the work in time & 10 \\
5 & Finishing the work in time & 10 \\
6 & Following the instructions & 5 \\
7 & Observance of work safety regulations & 5 \\
8 & The occurrence of work accident & 20 \\
9 & The occurrence of near-miss events & 5 \\
10 & Communication with stakeholders & 5 \\
11 & Environmental conscience & 5 \\
12 & Deficiency amount in receiving & 5 \\
13 & Method and speed for solving the problems & 5 \\
14 & Use of construction equipment & 5 \\
15 & Material loss & 5 \\
\hline & & 100 \\
\hline
\end{tabular}

Subcontractors are evaluated by the contractor technical personnel in accordance with the criteria given in Table 3 regarding the work they perform in each project. As a result of the assessment, sub-contractor quality scores are obtained and this scoring is used in the selection of sub-contractors for other works. Table 4 presents an example of a quality assessment for a ceiling floor subcontractor. Similarly, quality scores were also obtained for other works. The quality values of the alternatives for the problem dealt with in this study are given in Table 5. 
Table 4. Ceiling floor quality components for the case study (Isikyildiz, 2019).

\begin{tabular}{|c|c|c|c|c|c|c|c|c|}
\hline \multirow{2}{*}{\multicolumn{2}{|c|}{ Quality components of ceiling floor }} & \multirow{4}{*}{$\begin{array}{c}\text { Point \% } \\
5\end{array}$} & & \multicolumn{5}{|c|}{ Alternatives } \\
\hline & & & & 1 & 2 & 3 & 4 & 5 \\
\hline \multirow{2}{*}{1} & \multirow{2}{*}{ Quality standard certificates } & & Point & 85 & 75 & 95 & 85 & 95 \\
\hline & & & Percentage value & 4.3 & 3.8 & 4.8 & 4.3 & 4.3 \\
\hline \multirow{2}{*}{2} & \multirow{2}{*}{ Equipment (Technology- Innovation) } & \multirow{2}{*}{5} & Point & 95 & 80 & 95 & 75 & 90 \\
\hline & & & Percentage value & 4.5 & 4 & 4.8 & 3.8 & 4.5 \\
\hline \multirow{2}{*}{3} & \multirow{2}{*}{ Technical personnel capacity } & \multirow{2}{*}{5} & Point & 80 & 90 & 90 & 70 & 95 \\
\hline & & & Percentage value & 4 & 4.5 & 4.5 & 3.5 & 4.8 \\
\hline \multirow{2}{*}{4} & \multirow{2}{*}{ Starting the work in time } & \multirow{2}{*}{10} & Point & 60 & 90 & 55 & 75 & 90 \\
\hline & & & Percentage value & 6 & 9 & 5.5 & 7.5 & 9 \\
\hline \multirow{2}{*}{5} & \multirow{2}{*}{ Finishing the work in time } & \multirow{2}{*}{10} & Point & 75 & 75 & 60 & 60 & 85 \\
\hline & & & Percentage value & 7.5 & 7.5 & 6 & 6 & 8.5 \\
\hline \multirow{2}{*}{6} & \multirow{2}{*}{ Following the instructions } & \multirow{2}{*}{5} & Point & 75 & 80 & 70 & 55 & 85 \\
\hline & & & Percentage value & 3.8 & 4 & 3.5 & 2.8 & 4.3 \\
\hline \multirow{2}{*}{7} & \multirow{2}{*}{ Observance of work safety regulations } & \multirow{2}{*}{5} & Point & 75 & 85 & 65 & 55 & 95 \\
\hline & & & Percentage value & 3.8 & 4.3 & 3.3 & 2.8 & 4.8 \\
\hline \multirow{2}{*}{8} & \multirow{2}{*}{ The occurrence of work accident } & \multirow{2}{*}{20} & Point & 55 & 80 & 60 & 55 & 80 \\
\hline & & & Percentage value & 11 & 16 & 12 & 11 & 16 \\
\hline \multirow{2}{*}{9} & \multirow{2}{*}{ The occurrence of near-miss events } & & Point & 90 & 80 & 50 & 50 & 95 \\
\hline & & 5 & Percentage value & 4.5 & 4 & 2.5 & 2.5 & 4.8 \\
\hline 10 & Communication with stakeholders & 5 & Point & 90 & 80 & 70 & 50 & 95 \\
\hline 10 & communication witn stakenolders & 5 & Percentage value & 4.5 & 4 & 4.3 & 2.5 & 4.3 \\
\hline 11 & Environmental conscience & 5 & Point & 90 & 80 & 85 & 50 & 95 \\
\hline 11 & environmental conscience & 3 & Percentage value & 4.5 & 4 & 4.3 & 2.5 & 4.3 \\
\hline 12 & Deficiency amount in receiving & 5 & Point & 90 & 80 & 80 & 60 & 95 \\
\hline 12 & 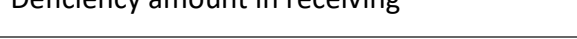 & J & Percentage value & 4.5 & 4 & 4 & 3 & 4.3 \\
\hline 12 & Method and speed for solving the problems & 5 & Point & 90 & 70 & 70 & 50 & 95 \\
\hline 13 & & 5 & Percentage value & 4.5 & 3.5 & 3.5 & 2.5 & 4.3 \\
\hline 14 & Use of construction equinment & 5 & Point & 90 & 80 & 80 & 70 & 95 \\
\hline 14 & Use or construction equipment & 5 & Percentage value & 4.5 & 4 & 4 & 3.5 & 4.3 \\
\hline 15 & Material loss & 5 & Point & 65 & 70 & 80 & 40 & 100 \\
\hline 15 & IVlaterial Ioss & 5 & Percentage value & 3.3 & 3.5 & 4 & 2 & 5 \\
\hline Tota & yuality value \% & & & 75 & 80 & 70 & 60 & 90 \\
\hline
\end{tabular}

Table 5. Problem database for the case study (Isikyildiz, 2019).

\begin{tabular}{|c|c|c|c|c|c|c|}
\hline \multirow{2}{*}{$\begin{array}{l}\text { Activity } \\
\text { ID }\end{array}$} & \multirow{2}{*}{ Activity name } & Alternative 1 & Alternative 2 & Alternative 3 & Alternative 4 & Alternative 5 \\
\hline & & \multicolumn{5}{|c|}{ Quality \% } \\
\hline$A$ & Construction site delivery & - & - & - & - & - \\
\hline $\mathrm{B}$ & Mobilization & 80 & 70 & - & - & - \\
\hline $\mathrm{C}$ & Excavation & 80 & 95 & 85 & 70 & - \\
\hline $\mathrm{D}$ & Foundation & 70 & 80 & 90 & - & - \\
\hline$E$ & Concrete works & 70 & 60 & 80 & 90 & - \\
\hline $\mathrm{F}$ & $\begin{array}{l}\text { Electric conduit in Wall } \\
\text { and Ceiling }\end{array}$ & 85 & 95 & 80 & - & - \\
\hline G & Wall works & 70 & 80 & 80 & 90 & - \\
\hline $\mathrm{H}$ & Screed concrete & 80 & 90 & 70 & - & - \\
\hline 1 & Heating installation & 75 & 80 & 70 & 90 & - \\
\hline$J$ & Sanitary installation & 90 & 80 & 70 & 60 & 50 \\
\hline K & Tile & 70 & 95 & 85 & - & - \\
\hline $\mathrm{L}$ & Door and window works & 70 & 80 & 60 & 80 & 95 \\
\hline $\mathrm{M}$ & Plaster works & 80 & 70 & 90 & 60 & - \\
\hline $\mathrm{N}$ & Ceiling Floor & 75 & 80 & 70 & 60 & 90 \\
\hline $\mathrm{O}$ & Satin Paint & 80 & 90 & 70 & 50 & - \\
\hline
\end{tabular}




\section{Solution of the problem}

To solve the sample problem, the genetic algorithm code was improved and implemented in Matlab inconsistent with a multi-purpose multi-alternative optimization problem. Figure 3 shows the flow chart of the project implementation. The crossover rate is generally between $0.7-1$ in the literature and the mutation rate is a range of $0.01-0.1$. In this study, the crossover ratio was selected as 1 and the mutation ratio was used as 0.05 for the solution of the optimization problem. The initial population for the genetic algorithm system was composed of 50, 100, 500, and 1000 individuals.

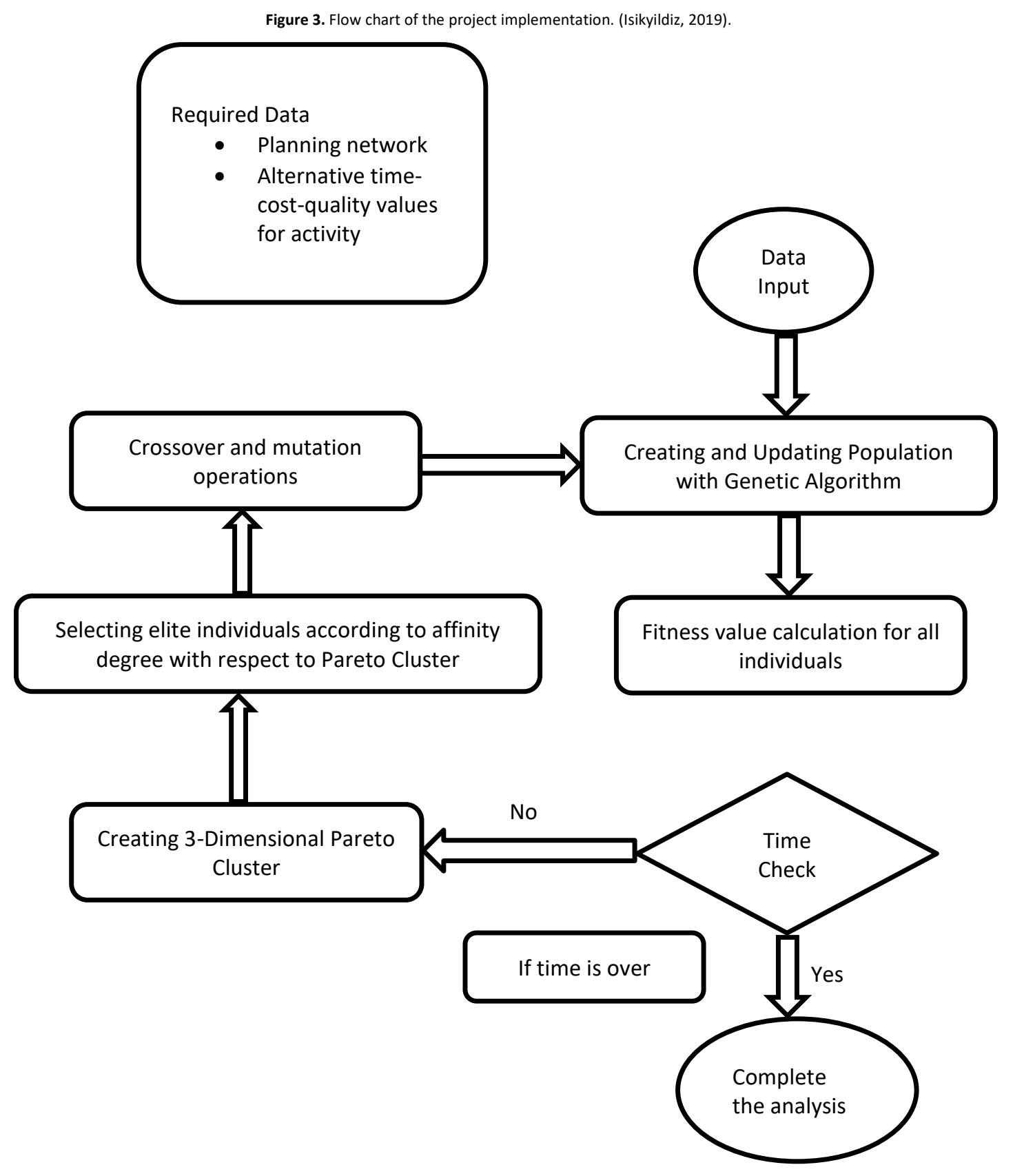

\section{Calculation of Fitness Function}

In this study, CPM back-and-forth calculations as fitness functions were generated with Matlab code for each chromosome. Total project duration, total cost, and average quality information for the alternatives being composed of all chromosomes were calculated. Provided that all activities are carried out, just before and after activities of the main activities, and the critical path calculation is included in the fitness function. 


\section{Creating the Initial Population}

In solutions developed using meta-heuristic algorithms, generally, the initial population is created with the results of other heuristics or random selection. In this study, the initial population is randomly generated in the time-cost-quality optimization problem. Chromosomes are defined as vectors and the population matrix is obtained. The cost, duration and quality matrices corresponding to each gene in the random initial population were created separately in Matlab. Matrices for time, cost and quality data, which are the alternative values of the project activities, were also created in Matlab, separately. For the activities in the project, previous activities were determined and the fitness function was applied in Matlab performing their back and forth calculations. For each possible project time period, initial population values that would allow activities to choose different values from time, cost, and quality alternatives were applied by a using genetic algorithm in Matlab. The emerging set of solutions was plotted by Matlab. For each project time period, the detailed table of time, cost, and quality alternatives for the solutions was created by Matlab. A new CPM schedule was created maintaining priority values for each project duration. After the initial population is formed, a project time is formed with the alternative components of each of the chromosomes as well as the resulting Pareto image. Each project has its unique total duration, total cost value, and average quality percentage.

It is possible to stop the analysis by checking whether it meets the stopping criterion. Convergence to a defined objective function value, expiration of any given time, number of iterations, or number of iterations that do not produce a better solution can be used as a stopping criterion. In this study, time was assigned as a stopping criterion. The process is repeated throughout the whole iterations, and the resulting values may be optimum or near optimum. Even though meta-heuristic methods cannot provide optimum results, they can guarantee near-optimum solutions for sufficient time periods. The genetic algorithm aims to reach the optimum result by improving the solutions with each iteration or transmitting the good solutions in the previous iteration to the next one by an elitist approach. Each generation produces individuals in the same number of initial population and solutions are explored within this population. In this study, data of the application problem was used in GA by developing a fitness function code. In addition, optional solutions and Pareto images were created in Matlab changing the initial population values of the application problem.

\section{Results and Discussion}

In terms of implementation, the most important issues in the construction market are project duration and project cost. In the scope of this study, quality values were also included in the analyzes of these two important factors. Project cost and duration generally vary in inverse proportion to each other. The cost will increase as it will be required to increase the number of teams in order to shorten the project duration. The possibility of a reduction in quality values with the shortening of time exists, as well. On the other hand, the increasing quality will also cause an increase in costs. The interaction of these three factors is quite complex. The purpose of the project is to minimize the duration and cost, while the quality value is aimed to be at the highest point. Taking into consideration these three factors, it becomes more difficult to find the optimum solution as the number of project activities and the time, cost and quality alternatives increase. In the multi-purpose and multi-alternative optimization problem, it was aimed to decrease the project cost and duration, and to increase quality values. In the scope of this study, it was aimed to obtain Pareto solutions with different numbers of the initial population using the data of the application project and the results of the analyses were evaluated. Running the GA algorithm properly, many optimal solutions have been accomplished. Since the case in this study is a multipurpose optimization problem, it is expected that more than one optimal solution comes out. Figure 4 shows the 3D graphs of the analysis results with 50, 100, 500, and 1000 populations. It was observed that as the initial population value increased, the number of solution alternatives also increased.

It was observed that, with the increase of population, repetition of solutions and time loss come out for analyses including more than 1000 populations. In order to increase alternative solutions and to reach the most efficient results, it was decided to keep on using, as an optimal choice, 1000 populations for the case problem including 15 activities and 5 alternatives. As can be seen in Figure 4, when the data was fed to the system with the initial population value of 50 and the genetic algorithm was run, 103 generations were created and 18 Pareto images were recorded. In addition, 105 generations were produced and 35 Pareto images were recorded for running of genetic algorithm with the initial population value of 100 . For the initial population value of 500, 102 generations were generated and 175 Pareto images were recorded. Finally, when the data was input to the system with the initial population value of 1000 and the genetic algorithm was operated, 91 generations were produced and 350pareto images were recorded. The results were unexceptionally repeated when the initial population value is selected more than 1000 . All Pareto results obtained from the analysis are optimal solutions. They are incomparable and do not dominate each other. Selecting the most appropriate solution depends entirely on the decision of the project manager. For example, if the project manager seeks the average quality of the project to be over $80 \%$, and decides to choose between the Pareto solutions that come out 
of the analysis according to the second-degree cost priority, there are 86 Pareto solutions with a quality average of over $80 \%$. The details for the best 20 Pareto solutions in terms of minimum cost and minimum time are given in Table 6.

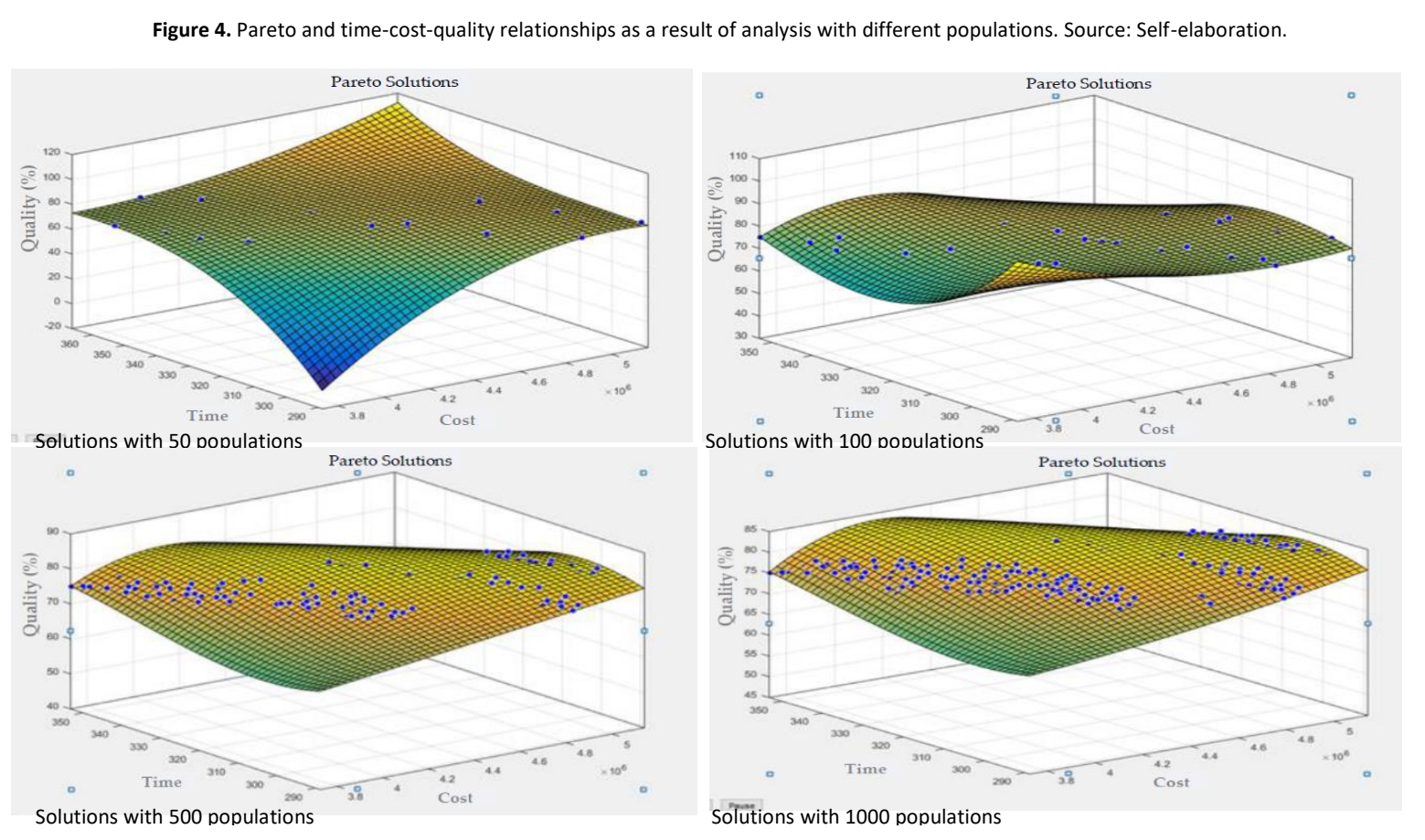

\begin{tabular}{|c|c|c|c|c|c|c|c|c|c|c|c|c|c|c|c|c|c|c|}
\hline \multirow{2}{*}{$\begin{array}{c}\text { Pareto } \\
\text { Numbers }\end{array}$} & \multirow{2}{*}{ Time } & \multirow{2}{*}{ Cost (USD) } & \multirow{2}{*}{ Quality\% } & \multicolumn{15}{|c|}{ Activity IDs and the alternative order in which they belong } \\
\hline & & & & A & B & C & D & $\mathrm{E}$ & $\mathrm{F}$ & G & $\mathrm{H}$ & I & J & K & L & M & $\mathrm{N}$ & $\mathrm{O}$ \\
\hline 1 & 332 & 863000 & 83 & 1 & 1 & 2 & 3 & 3 & 2 & 4 & 2 & 4 & 1 & 2 & 5 & 3 & 3 & 2 \\
\hline 2 & 328 & 874400 & 83 & 1 & 1 & 2 & 3 & 3 & 2 & 2 & 2 & 4 & 1 & 2 & 5 & 3 & 2 & 2 \\
\hline 3 & 328 & 877600 & 83 & 1 & 1 & 2 & 3 & 3 & 2 & 4 & 2 & 2 & 1 & 2 & 5 & 3 & 5 & 2 \\
\hline 4 & 326 & 879000 & 83 & 1 & 1 & 2 & 3 & 3 & 2 & 4 & 2 & 4 & 1 & 2 & 5 & 3 & 2 & 2 \\
\hline 5 & 324 & 883000 & 83 & 1 & 1 & 2 & 3 & 3 & 2 & 4 & 2 & 4 & 3 & 2 & 5 & 3 & 5 & 2 \\
\hline 6 & 323 & 886000 & 83 & 1 & 1 & 3 & 3 & 3 & 2 & 4 & 2 & 4 & 1 & 2 & 5 & 3 & 2 & 2 \\
\hline 7 & 324 & 887000 & 84 & 1 & 1 & 2 & 3 & 3 & 2 & 4 & 2 & 4 & 1 & 2 & 5 & 3 & 5 & 3 \\
\hline 8 & 321 & 888000 & 83 & 1 & 1 & 2 & 3 & 3 & 2 & 4 & 2 & 3 & 1 & 2 & 5 & 3 & 5 & 2 \\
\hline 9 & 319 & 893000 & 83 & 1 & 1 & 2 & 3 & 3 & 2 & 4 & 2 & 4 & 1 & 2 & 5 & 3 & 5 & 2 \\
\hline 10 & 321 & 894000 & 83 & 1 & 1 & 3 & 3 & 3 & 2 & 4 & 2 & 4 & 1 & 2 & 5 & 3 & 5 & 2 \\
\hline 11 & 320 & 900000 & 83 & 1 & 1 & 2 & 2 & 3 & 2 & 4 & 2 & 4 & 1 & 2 & 5 & 3 & 5 & 2 \\
\hline 12 & 317 & 901000 & 83 & 1 & 1 & 2 & 3 & 3 & 3 & 4 & 2 & 4 & 1 & 2 & 5 & 3 & 5 & 2 \\
\hline 13 & 308 & 936600 & 83 & 1 & 1 & 4 & 3 & 4 & 2 & 4 & 2 & 4 & 1 & 2 & 5 & 3 & 5 & 2 \\
\hline 14 & 317 & 974400 & 83 & 1 & 1 & 2 & 3 & 4 & 2 & 2 & 2 & 4 & 1 & 2 & 5 & 3 & 2 & 2 \\
\hline 15 & 315 & 979000 & 84 & 1 & 1 & 2 & 3 & 4 & 2 & 4 & 2 & 4 & 1 & 2 & 5 & 3 & 2 & 2 \\
\hline 16 & 313 & 983000 & 83 & 1 & 1 & 2 & 3 & 4 & 2 & 4 & 2 & 4 & 3 & 2 & 5 & 3 & 5 & 2 \\
\hline 17 & 312 & 986000 & 83 & 1 & 1 & 3 & 3 & 4 & 2 & 4 & 2 & 4 & 1 & 2 & 5 & 3 & 2 & 2 \\
\hline 18 & 313 & 987000 & 85 & 1 & 1 & 2 & 3 & 4 & 2 & 4 & 2 & 4 & 1 & 2 & 5 & 3 & 5 & 2 \\
\hline 19 & 310 & 988000 & 83 & 1 & 1 & 2 & 3 & 4 & 2 & 4 & 2 & 3 & 1 & 2 & 5 & 3 & 5 & 2 \\
\hline 20 & 308 & 993000 & 83 & 1 & 1 & 2 & 3 & 4 & 2 & 4 & 2 & 4 & 1 & 2 & 5 & 3 & 5 & 3 \\
\hline
\end{tabular}


Activity options, which compose the project, belong to the best 20 Pareto images according to constraints defined by the manager are presented in Table 6. If the manager aims to minimize the project cost and the duration of the project is not critically important, he/she should choose the first solution with $83 \%$ average quality, 332 days duration, and 863000 USD cost. Accordingly, the main contractor should use the corresponding contractor planning in order to obtain the first Pareto solutions as shown in Figure 4 (Hence, the sub-contractor array will have a form of A:1, B:1, C:2, D:3; $\mathrm{E}: 3 ; \mathrm{F}: 2 ; \mathrm{G}: 4 ; \mathrm{H}: 2 ; \mathrm{I}: 4 ; \mathrm{J}: 1 ; \mathrm{K}: 2 ; \mathrm{L}: 5 ; \mathrm{M}: 3 ; \mathrm{N}: 3 ; \mathrm{O}: 2$. Likewise, the decision-maker can choose any of the Pareto optimum solutions given to meet the priorities and objectives of the project.

\section{Conclusions}

A multi-purpose multi-alternative optimization model has been developed for three-dimensional time-cost-quality tradeoff analysis, instead of the traditional two-dimensional time-cost analysis method. This model seeks optimal resource utilization plans that minimize construction time and cost besides maximizing quality. In the case study of this work, a time-cost-quality trade-off problem of a real construction project is examined and solved. In order to solve a multi-purpose and multi-alternative optimization problem, a genetic algorithm consisting of evolutionary-based metaheuristics was used by writing computer code in Matlab. The effect of population size on Pareto value was also investigated in GA applied to the problem of this study. The number of Pareto images increased with an increase in the number of populations. Time constraint was created while the iteration number was not considered as a constraint. The mutation value was used as 0.05 as in general GA applications. Therefore, the optimal results for the problem in the application project could be obtained with 1000 populations. The number of populations varies according to the data size and the constraints defined in each problem.

Comparing the results for the populations in the problem, the option with the shortest time period and minimum cost exist in the application with 100 and 1000 populations. In terms of the cost, the minimum cost with the same value in all populations and, therefore, the minimum duration for the project was reached. However, for the quality value, the target has not been met for 50 populations and the quality value remained lower than that of the other populations. Considering the quality, the maximum quality value was reached with 1000 populations. Taking all three criteria into consideration, the most appropriate results for this problem were reached with 1000 populations. Huge numbers of time, cost, and quality combinations, which is highly excessive for being created by the manager, were generated and this study met, in a general manner, the objective. As a result of the investigations and analyses, it was observed that there is no single solution to this problem. Obtaining a solution which provides minimum time and cost, and maximum quality is not possible. Along with the Pareto front, the solution sets are created. The most accurate solution changes according to the requests of the project manager. Within the set of solutions, the project manager is given the chance to make a choice according to which time, cost, and quality values take priority or which criteria are prioritized for the activities which can also be divided into sub-groups.

Choosing the right subcontractor for a specific work is also a crucial decision-making problem in the construction industry. In this study, a genetic algorithm has been developed to assist the main contractors in the selection of the most appropriate sub-contractors to carry out different work items considering the trade-off between time-cost-quality in a construction project. The Pareto-optimal solutions obtained from the analysis showed that the developed GA algorithm works properly and produces convincing results.

In future research, thousands of the solutions created on the Pareto front can be classified with a different method. Activities can also be grouped in such a way that they can be evaluated in terms of different selection priorities. The software can be developed and used actively in the construction industry to carry out this task.

\section{References}

Aminbakhsh, S., Sönmez, R., \& Bilir, M. (2016). Tamsayılı Doğrusal Programlama Yöntemiyle Kesikli Zaman-Maliyet Ödünleşim Probleminin Optimal Pareto Çözümü [Optimal pareto solution of discrete time-cost trade-off problem with integer linear programming method]. 4th Project and Construction Management Congress, 281-292.

Bettemir, O. H. (2011). Experimental design for genetic algorithm simulated annealing for time-cost trade-off problems. International Journal of Engineering \& Applied Sciences (IJEAS), 3(1), 15-26.

Bingol, B. N., \& Polat, G. (2015). Time-cost-quality trade-off model for subcontractor selection using discrete particle swarm optimization algorithm. In Thirty-First Annual Conference, September, 13-22.

Dorigo, M., \& Stutzle, T. (2004). Ant Colony Optimization. Massachusetts Institute of Technology.

Easa, S. M. (1989). Resource leveling in construction by optimization. Journal of Constructıon Engıneerıng and Management, 115(2), 302-316. 
El-rayes, B. K. (2001). optimum planning of highway construction A+B bidding method. Journal of Computing in Civil Engineering, 127(August), 261269.

El-rayes, K., \& Kandil, A. (2005). Time-cost-quality trade-off analysis for highway construction. Journal of Construction Engineering and Management, $131(4), 477-486$.

Geem, Z. W. (2010). Multiobjective optimization of time-cost trade-off using harmony search. Journal of Computing in Civil Engineering, 136(June), 711-716.

Goldberg, D. E. (1989). Genetic algorithms in search, optimization, and machine learning (2nd ed.). Addison-Wesley Publishing Company, Inc.

Gomar, J. E., Haas, C. T., \& Morton, D. P. (2002). Assignment and allocation optimization of partially multiskilled workforce. Journal of Constructıon Engıneerıng and Management, 128(April), 103-109.

Hegazy, T. (1999). Optimization of resource allocation and leveling using genetic algorithms. Journal of Constructıon Engıneerıng and Management, 125(June), 167-175.

Hegazy, T., \& Wassef, N. (2001). Cost optimization in projects with repetitive nonserial activities. Journal of Construction Engineering and Management, 127(June), 183-191.

Iscioglu, Y. (2011). Time - cost - quality optimization in a residential project by using fuzzy logic decision - making method. In Doctoral dissertation, ITU Institute of Science.

Isikyildiz, S. (2019). Time-cost-quality optimization with a meta-heuristic approach in construction projects. (Master's thesis). Retrieved from Turkey Council of Higher Education Thesis Center Database. (Accession No. 578147).

Magalhães-mendes, J. (2017). Multiobjective optimization of road construction project time-cost-quality trade-off using genetic algorithms. In Congress on Numerical Methods in Engineering CMN2017, 3-5 July.

Sari, T. (2008). Metasezgisel yöntemlerle proje çizelgeleme optimizasyonu [Project scheduling optimization with metaheuristic methods]. Marmara University (Master's thesis). Retrieved from Turkey Council of Higher Education Thesis Center Database. (Accession No. 226628).

Sivanandam, D., \& Deepa, S. N. (2008). Introduction to genetic algorithms. Springer Berlin Heidelberg New York.

Sorrentino, M. (2013). Genetic algorithms for construction time-cost-quality trade-off : a road project case study. Construction Management, 4(2), 163-176.

Togan, V., \& Eirgash, M. A. (2019). Time-cost trade-off optimization of construction projects using teaching-learning based optimization. KSCE Journal of Civil Engineering, 23(1), 10-20. https://doi.org/10.1007/s12205-018-1670-6

Yang, X.-S. (2010). Engineering optimization: an Introduction with metaheuristic applications. (1st ed.). John Wiley \& Sons, Inc.

Zalmai, M. L., Akcay, C., \& Manisali, E. (2019). Time-cost optimization using harmony search algorithm in construction projects. Journal of Construction, 226-237. https://doi.org/10.7764/RDLC.18.2.226

Zhang, H., \& Li, H. (2010). Multi-objective particle swarm optimization for construction time-cost trade-off problems. Construction Management and Economics, 6193. https://doi.org/10.1080/01446190903406170

Zheng, D. X. M., Ng, S. T., \& Kumaraswamy, M. M. (2005). Applying Pareto ranking and niche formation to genetic algorithm-based multiobjective time - cost optimization. Journal of Constructıon Engıneerıng and Management, 131(1), 81-91.

\section{Appendix: Concepts of genetic algorithms and definitions of operators}

Gene: Each of the parameters of a solution. They are hereditary units that characterize the organism.

Allele: The value of genes.

Locus: The position of the gene on the chromosome.

Chromosome: The sequence formed by the combination of more than one gene is each individual showing possible solutions.

Population: A collection of chromosomes showing possible solutions to a problem.

Suitability value: The evaluation of each chromosome using the suitability function (often the objective function) is the performance score obtained.

Selection: Selection of the most successful solutions in a population for reproduction with a selection algorithm based on the suitability value.

Crossover: Randomly mixed parts of two different solutions to derive new solutions.

Mutation: It is the alteration of the gene structure of a random candidate solution. 